Accepted for publication in the Journal of Applied Physics.

\title{
Calculation of thermodynamic, electronic, and optical properties of monoclinic $\mathrm{Mg}_{2} \mathrm{NiH}_{4}$
}

\author{
W. R. Myers, T. J. Richardson, and M. D. Rubin \\ Building Technologies Department \\ Environmental Energy Technologies Division
}

\author{
L-W. Wang \\ National Energy Research Scientific Computing Center \\ Ernest Orlando Lawrence Berkeley National Laboratory \\ University of California \\ 1 Cyclotron Road \\ Berkeley, California 94720
}

October 2001

This work was supported by the Assistant Secretary for Energy Efficiency and Renewable Energy, Office of Building Technology, State and Community Programs, Office of Building Research and Standards of the US Department of Energy under Contract No. DE-AC03-76SF00098. This research used resources of the National Energy Research Scientific Computing Center, which is supported by the Office of Science of the U.S. Department of Energy. Work at NERSC was supported by the Director, Office of Science, Division of Mathematical, Information, and Computational Science of the U.S. Department of Energy under Contract number DE-AC0376 SF00098. 


\title{
Calculation of thermodynamic, electronic, and optical properties of monoclinic $\mathrm{Mg}_{2} \mathrm{NiH}_{4}$
}

\author{
W. R. Myers, L-W. Wang, T. J. Richardson*, and M. D. Rubin
}

\begin{abstract}
Ab initio total-energy density functional theory is used to investigate the low temperature (LT) monoclinic form of $\mathrm{Mg}_{2} \mathrm{NiH}_{4}$. The calculated minimum energy geometry of $\mathrm{LT} \mathrm{Mg}_{2} \mathrm{NiH}_{4}$ is close to that determined from neutron diffraction data, and the $\mathrm{NiH}_{4}$ complex is close to a regular tetrahedron. The enthalpies of the phase change to high temperature (HT) pseudo-cubic $\mathrm{Mg}_{2} \mathrm{NiH}_{4}$ and of hydrogen absorption by $\mathrm{Mg}_{2} \mathrm{Ni}$ are calculated and compared with experimental values. $\mathrm{LT} \mathrm{Mg}_{2} \mathrm{NiH}_{4}$ is found to be a semiconductor with an indirect band gap of $1.4 \mathrm{eV}$. The optical dielectric function of LT $\mathrm{Mg}_{2} \mathrm{NiH}_{4}$ differs somewhat from that of the HT phase. A calculated thin film transmittance spectrum is consistent with an experimental spectrum.
\end{abstract}

\section{Introduction}

The metallic nickel-magnesium alloy $\mathrm{Mg}_{2} \mathrm{Ni}$ absorbs hydrogen to form semiconducting $\mathrm{Mg}_{2} \mathrm{NiH}_{4}{ }^{1}$ Because of its low weight and high hydrogen content, $\mathrm{Mg}_{2} \mathrm{NiH}_{4}$ has been intensively investigated both theoretically and experimentally as a hydrogen storage material. Recently, Richardson reported ${ }^{2}$ that thin nickel-magnesium films can behave as switchable mirrors. A magnesium-rich $\mathrm{Mg}$-Ni film of sufficient thickness reflects or absorbs all incident light. Upon exposure to gaseous hydrogen or on cathodic polarization in an alkaline electrolyte, the film becomes transparent. ${ }^{3}$ On subsequent exposure to air, or when polarized anodically, the film reverts to its original metallic state.

$\mathrm{Mg}_{2} \mathrm{NiH}_{4}$ transforms from a high temperature (HT) cubic structure to a low temperature (LT) monoclinic phase between $245^{\circ}$ and $210^{\circ} \mathrm{C}^{4}$ Significant structural and electronic differences may exist between the HT and LT phases. Most previous studies, especially theoretical calculations ${ }^{5-8}$ have concentrated on the simpler HT phase, which has seven atoms per unit cell. The ambient temperature electrochromic application of $\mathrm{Mg}_{2} \mathrm{NiH}_{4}$ suggests the need for theoretical investigation of the LT phase, especially of its electronic and optical properties. In

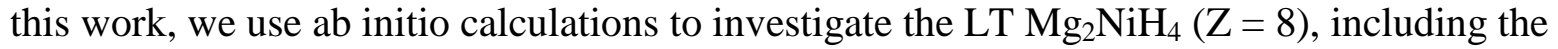
atomic positions, formation enthalpy relative to $\mathrm{Mg}_{2} \mathrm{Ni}$ and $\mathrm{HT} \mathrm{Mg}_{2} \mathrm{NiH}_{4}$, electronic band structure, and optical spectrum.

When hydrogen is absorbed by $\mathrm{Mg}_{2} \mathrm{Ni}$ beyond $0.3 \mathrm{H}$ per unit formula, the system undergoes a structural rearrangement to the stoichiometric complex hydride $\mathrm{Mg}_{2} \mathrm{NiH}_{4}$, with an accompanying $32 \%$ increase in volume. The primary cell of $\mathrm{LT} \mathrm{Mg}_{2} \mathrm{NiH}_{4}$, containing 56 atoms is quite large for ab initio calculation. Calculations for such systems have recently become practical through the advances algorithms and development of parallel supercomputers. The current study represents our first step towards the direct theoretical investigation of these complex hydride systems via large-scale computations.

*tjrichardson@lbl.gov 
Garcia et al. ${ }^{8}$ studied $\mathrm{HT} \mathrm{Mg}_{2} \mathrm{NiH}_{4}$, which contains seven atoms per primary unit cell, using density functional theory. The structure of $\mathrm{HT} \mathrm{Mg} \mathrm{NiD}_{4}$ has been studied by neutron diffraction. ${ }^{9,10}$ The metal atoms exhibit an antifluorite arrangement, with $\mathrm{NiH}_{4}$ units surrounded by $\mathrm{Mg}$ at the corners of a cube. The precise location of the deuterium atoms, however, could not be determined. Using a local density approximation (LDA) of the density functional theory, Garcia et al. found that the $4 \mathrm{H}$ atoms surrounding the $\mathrm{Ni}$ atom form a distorted tetrahedron. The calculated length of the $\mathrm{Ni}-\mathrm{H}$ bond is about $1.548 \mathrm{~A}$, in reasonable agreement with the neutron diffraction results. That work demonstrates the usefulness of density functional calculations in studying such systems. Here we apply the technique to $\mathrm{LT} \mathrm{Mg}_{2} \mathrm{NiH}_{4}$.

The issues we wish to address concerning LT $\mathrm{Mg}_{2} \mathrm{NiH}_{4}$ are: (1) The equilibrium atomic structure for comparison with experimental x-ray and neutron diffraction results. Ab initio LDA calculation has become a standard theoretical tool in recent years to investigate such structure information. While Garcia found that the $4 \mathrm{H}$ atoms in $\mathrm{HT} \mathrm{Mg}_{2} \mathrm{NiH}_{4}$ form a distorted tetrahedron around $\mathrm{Ni}$, the neutron diffraction data for $\mathrm{LT} \mathrm{Mg}_{2} \mathrm{NiH}_{4}$ are consistent with a nearly ideal $\mathrm{NiH}_{4}$ tetrahedron. (2) The enthalpy of formation of $\mathrm{LT} \mathrm{Mg}_{2} \mathrm{NiH}_{4}$ from $\mathrm{Mg}_{2} \mathrm{Ni}\left(+2 \mathrm{H}_{2}\right)$ and from $\mathrm{HT}$ $\mathrm{Mg}_{2} \mathrm{NiH}_{4}$. This can be calculated from the total energies of the respective materials and compared directly with experimental values. Further investigation in the future along this line may illuminate the mechanism of hydrogen uptake by $\mathrm{Mg}_{2} \mathrm{Ni}$, which is important for both hydrogen storage and electrochromic applications. (3) The electronic structure and optical properties of $\mathrm{LT} \mathrm{Mg}_{2} \mathrm{NiH}_{4}$. Garcia showed that the $\mathrm{NiH}_{4}$ configuration has a significant effect on the band structure of $\mathrm{HT} \mathrm{Mg}_{2} \mathrm{NiH}_{4}$, with the lowest energy configuration being semi-metallic. Here we compare the electronic band structure of $\mathrm{LT} \mathrm{Mg}_{2} \mathrm{NiH}_{4}$ to that calculated by Garcia for HT $\mathrm{Mg}_{2} \mathrm{NiH}_{4}$. We also compute optical properties of both phases and compare them to an experimental thin film transmission measurement.

We performed calculations using two different computational methods: full potential linear augmented plane wave (LAPW) and pseudopotential plane wave (PW). These two methods use different basis sets for the wave functions and treat the real space charge density and potential differently. While LAPW is generally considered to be the more reliable of the two and is often used for transition metal calculations, it scales poorly for larger systems. To test the reliability of the PW method, we have first compared the LAPW and PW methods for smaller systems (e.g., $\mathrm{HT} \mathrm{Mg}_{2} \mathrm{NiH}_{4}$ ).

\section{Structural Differences Between HT and LT $\mathrm{Mg}_{2} \mathrm{NiH}_{4}$}

The atomic structure of $\mathrm{HT} \mathrm{Mg}_{2} \mathrm{NiH}_{4}$ has not been completely determined by diffraction methods due both to the incompatibility of the $\mathrm{NiH}_{4}$ unit with the cubic space group Fm3m and to the relationship between the neutron scattering lengths for $\mathrm{Mg}$ and $\mathrm{Ni}^{11}{ }^{11}$ It is clear, however, that $\mathrm{Mg}$ and $\mathrm{Ni}$ adopt an antifluorite arrangement, and that all four $\mathrm{H}$ atoms surround the $\mathrm{Ni}$ atom. Specifically, with $\mathrm{Ni}$ at the origin, the hydrogen atoms occupy positions $(d \cos \alpha, 0, d \sin \alpha),(0$, $d \cos \alpha,-d \sin \alpha),(-d \cos \alpha, 0, d \sin \alpha)$ and $(0,-d \cos \alpha,-d \sin \alpha)$ where $d$ is the nickel-hydrogen bond distance and $\alpha$ is a $\mathrm{Ni}-\mathrm{H}$ bond bending angle as in Ref. 8. Using the experimental lattice constant of $6.507 \AA$, Garcia examined the effect of varying $d$ and $\alpha$ on the total energy using the LAPW program WIEN97. ${ }^{12}$ The calculated value of $\mathrm{d}$ was $1.548 \AA$, which compares well with the experimental value for the deuteride, $\mathrm{Mg}_{2} \mathrm{NiD}_{4}$, of $1.49 \AA{ }^{10} \alpha$ was found to be $21.8^{\circ}$. This 
corresponds to a flattened tetrahedron that is closer to a planar structure than to a regular tetrahedron. This result is illustrated in Figure1(a).

The structural differences between HT and LT $\mathrm{Mg}_{2} \mathrm{NiH}_{4}$ [Figure 1(b), Ref 10, data for the deuteride] are substantial. The $\mathrm{CaF}_{2}$-type arrangement of the metal atoms is retained, but with considerable distortion. The $\mathrm{NiH}_{4}$ unit, however is close to a regular tetrahedron, with Ni-H bond lengths from 1.519 to $1.572 \AA$ (avg. 1.54) and H-Ni-H bond angles averaging $109.4^{\circ}$. The eight $\mathrm{NiH}_{4}$ complexes in each unit cell are crystallographically equivalent, but have four different orientations with respect to the crystal axes.
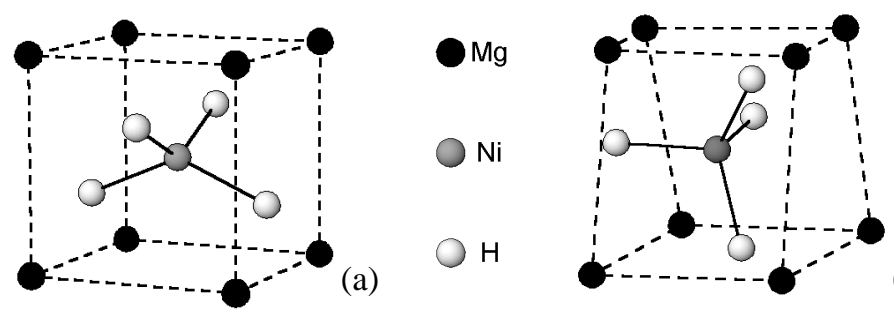

(b)

Figure 1. Local atomic structures of (a) $\mathrm{HT}$ cubic $\mathrm{Mg}_{2} \mathrm{NiH}_{4}$, (b) LT monoclinic $\mathrm{Mg}_{2} \mathrm{NiH}_{4}$.

\section{Computational Methods}

The local density approximation (LDA) ${ }^{14,15}$ was employed to calculate total energies and electronic structures in a manner similar to the work of Garcia. ${ }^{8}$ A plane wave (PW) basis was used to describe the wave functions with a kinetic energy cutoff of 67 Ryd. Trouillier-Martins norm conserving pseudopotentials ${ }^{16}$ were used to remove the core electrons from the calculations. Kleinman-Bylander nonlocal pseudopotentials in the plane wave code (Petot) ${ }^{17}$ implemented in real space, were used in the calculations. A conjugate-gradient algorithm was used to converge the electronic states, ${ }^{18}$ and a Pulay-Kerker charge mixing scheme was used to calculate the self-consistent charge density. After the Hellman-Feynman forces of the atoms were calculated, the Broyden-Fletcher-Goldfarb-Shanno (BFGS) algorithm ${ }^{19}$ was used to relax the atomic positions. Since neither $\mathrm{Mg}_{2} \mathrm{Ni}$ nor its hydride is magnetic, ${ }^{20}$ we have used LDA instead of the local spin density approximation. To compare the total energies for different crystal structures, we have used an equivalent k-point sampling scheme. ${ }^{21}$ This guarantees that different structures are treated equivalently. Specifically, we have used $4 \times 4 \times 4,2 \times 2 \times 2$, and $4 \times 4 \times 4$ Monkhorst-Pack k point grids for $\mathrm{Mg}_{2} \mathrm{Ni}$, LT $\mathrm{Mg}_{2} \mathrm{NiH}_{4}$ and $\mathrm{HT} \mathrm{Mg}_{2} \mathrm{NiH}_{4}$ respectively. After application of symmetry operations, these correspond to 14,8 , and 16 reduced k points. Since $\mathrm{Mg}_{2} \mathrm{Ni}$ is a metal, its k-point density is higher than of HT or LT $\mathrm{Mg}_{2} \mathrm{NiH}_{4}$. To calculate the density of states and optical properties, the converged systems were recalculated using denser k-

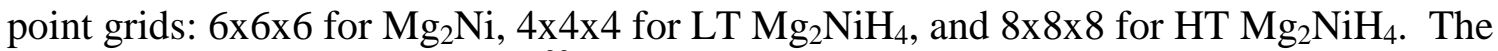
tetrahedral interpolation method ${ }^{22}$ was used to integrate over the first Brillouin zone based on the results from the above $\mathrm{k}$ point grids. The imaginary part of the dielectric constant was obtained by considering direct electronic transitions. ${ }^{23}$ The Kramers-Kronig relations yield the real part of the dielectric constant. We computed the directional average of the dielectric constant for comparison with a polycrystalline thin film. 
The computer program PEtot ${ }^{24}$ was used in the current calculation. It is parallelized based on a distribution of the plane wave coefficients to different processors. ${ }^{25}$ Using an efficient parallelized Fast Fourier Transformation (FFT) subroutine, the program was run on one hundred processors using a Cray T3E at the National Energy Research Scientific Computing Center (NERSC) at Lawrence Berkeley National Laboratory. Thousands of processor hours were

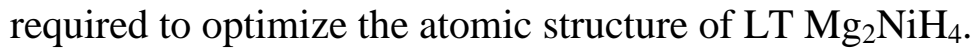

\section{Crystal Structure and Energy Minimization}

\section{$\mathrm{HT} \mathrm{Mg}_{2} \mathrm{NiH}_{4}$}

Here we have repeated the calculation of Garcia et al., but instead of using the LAPW method, we use the pseudopotential PW method. For electronic structure calculations involving transition metals, LAPW methods are used more often than pseudopotential PW methods and are considered to be more reliable. The LAPW method (including the WIEN97 code), however, does not scale favorably with the size of the system and the number of the processors in a parallel machine. Thus, we found it more efficient to study $\mathrm{LT} \mathrm{Mg}_{2} \mathrm{NiH}_{4}$ using the pseudopotential PW method. This required us to use a high kinetic energy cutoff (67 Ryd) for the PW basis. We calculated the energies of the three structures with different $\mathrm{NiH}_{4}$ configurations considered in Ref. 8. The results are compared with Garcia's LAPW results in Table 1. The tetrahedral structures were optimized according to their total energies. The energy orders of the three structures are the same for LAPW and PW calculations: distorted tetrahedral is lowest, followed by undistorted tetrahedral and then by square planar. For the distorted tetrahedral structure, the geometries from LAPW and PW are very similar: LAPW gave $1.548 \AA$, $21.8^{\circ}$ for $\mathrm{d}$ and $\alpha$, while PW gave $1.561 \AA$ and $23.6^{\circ}$. While there is some disagreement in the energy differences between structures calculated by the two methods, we believe the PW method is adequate for this application. Note that there are considerable uncertainties in the experimental determination of the LT structure, much like in the HT case. Therefore theoretical ab initio calculations can be very useful here.

Table 1. Energy (eV per formula unit) as a Function of Hydrogen Atom Configuration in HT $\mathrm{Mg}_{2} \mathrm{NiH}_{4}$ Relative to the Distorted Tetrahedral LAPW Minimum Energy Structure The correct LAPW energies are a factor of 4 higher $^{32}$ than those in Ref. 8.

\begin{tabular}{|c|c|c|c|c|}
\hline Hydrogen Geometry & $d(\AA)$ & $\underline{\alpha \text { (degrees) }}$ & PW Energy & $\underline{\text { LAPW Energy }}^{\text {a) }}$ \\
\hline Square Planar & 1.548 & 0.0 & 0.507 & 0.352 \\
\hline Dist. Tetr. LAPW & 1.548 & 21.8 & 0 & 0 \\
\hline Dist. Tetr. PW & 1.561 & 23.6 & -0.012 & - \\
\hline Tetrahedral & 1.516 & 35.3 & 0.203 & 0.260 \\
\hline
\end{tabular}

${ }^{a)}$ Ref. 8 


\section{$\mathrm{LT} \mathrm{Mg}_{2} \mathrm{NiH}_{4}$}

No previous ab initio structural calculations of $\mathrm{LT} \mathrm{Mg}_{2} \mathrm{NiH}_{4}$ appear to have been performed. This is probably because of the high computational requirement to relax a system with 56 atoms and 20 independent degrees of freedom. Starting with the experimental atomic positions ${ }^{13}$ and fixing the lattice constants of the unit cell, we minimized the energy by first relaxing the hydrogen atoms, then relaxing all atoms in the structure. Because the atoms started relatively far from their minimum energy positions and because of the large system size, this computation required dozens of line iterations and thousands of processor-hours to complete. While the only constraint on atomic motion was the preservation of inversion symmetry, the relaxed atomic

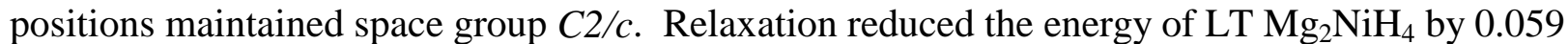
$\mathrm{eV} /$ formula unit from the experimental structure. In Table 2 the relaxed atomic positions are compared with the experimental (initial) values. The overall structure of $L T \mathrm{Mg}_{2} \mathrm{NiH}_{4}$ was preserved, with no change in symmetry. The maximum shift in atom position is about $0.14 \mathrm{~A}$ for $\mathrm{H}, 0.06 \mathrm{~A}$ for $\mathrm{Ni}$, and $0.12 \mathrm{~A}$ for $\mathrm{Mg}$. The $\mathrm{NiH}_{4}$ unit in the minimum energy configuration is nearer to a regular tetrahedron than in the experimental structure, with a narrower range of $\mathrm{Ni}-\mathrm{H}$ distances and angles (Table 3).

Table 2. Experimental and Minimum Energy Structures of $\mathrm{LT} \mathrm{Mg}_{2} \mathrm{NiH}_{4}$ With Space Group C2/C The experimental monoclinic cell constants ${ }^{13} a=14.343 \AA, b=6.4038 \AA, c=6.4830 \AA$, and $\square=113.52^{\circ}$ were used in both cases. $x, y, z$ are atomic coordinates in terms of lattice vectors $a, b, c$.

\begin{tabular}{|l|l|l|l|l|l|l|}
\cline { 2 - 7 } \multicolumn{1}{c|}{} & \multicolumn{3}{c|}{ Experimental } & \multicolumn{2}{c|}{ LDA Minimum Energy Structure } \\
\cline { 2 - 7 } \multicolumn{1}{c|}{} & \multicolumn{1}{c|}{$\mathrm{x}$} & $\mathrm{y}$ & $\mathrm{z}$ & $\mathrm{x}$ & $\mathrm{y}$ & $\mathrm{z}$ \\
\hline $\mathrm{Ni}$ in (8f) & $0.1194(6)$ & $0.2308(11)$ & $0.0832(12)$ & 0.1206 & 0.2267 & 0.0762 \\
\hline $\mathrm{Mg}(1)$ in (8f) & $0.2652(10)$ & $0.4827(24)$ & $0.0754(22)$ & 0.2659 & 0.4839 & 0.0890 \\
\hline $\mathrm{Mg}(2)$ in (4e) & 0 & $0.0144(33)$ & 0.25 & 0 & 0.0285 & 0.25 \\
\hline $\mathrm{Mg}(3)$ in (4e) & 0 & $0.5130(31)$ & 0.25 & 0 & 0.5316 & 0.25 \\
\hline $\mathrm{H}(1)$ in (8f) & $0.2113(14)$ & $0.2995(26)$ & $0.3037(28)$ & 0.2094 & 0.3018 & 0.3009 \\
\hline $\mathrm{H}(2)$ in (8f) & $0.1360(12)$ & $0.3163(18)$ & $0.8811(23)$ & 0.1393 & 0.3233 & 0.8763 \\
\hline $\mathrm{H}(3)$ in (8f) & $0.0105(11)$ & $0.2868(19)$ & $0.0537(22)$ & 0.0126 & 0.2922 & 0.0586 \\
\hline $\mathrm{H} \mathrm{(4)} \mathrm{in} \mathrm{(8f)}$ & $0.1306(12)$ & $0.9950(23)$ & $0.0815(23)$ & 0.1244 & 0.9871 & 0.0667 \\
\hline
\end{tabular}


Table 3. Comparison of Experimental ${ }^{13}$ And Minimum Energy LT Mg $\mathrm{NiH}_{4}$ Structures

\begin{tabular}{|c|c|c|}
\hline & Experimental & LDA Minimum Energy \\
\hline Energy (eV / formula unit) & 0 & -0.059 \\
\hline $\mathrm{Ni}-\mathrm{H}(1)$ bond length $(\AA)$ & 1.572 & 1.579 \\
\hline $\mathrm{Ni}-\mathrm{H}(2)$ bond length $(\AA)$ & 1.524 & 1.553 \\
\hline $\mathrm{Ni}-\mathrm{H}(3)$ bond length $(\AA)$ & 1.538 & 1.565 \\
\hline $\mathrm{Ni}-\mathrm{H}(4)$ bond length $(\AA)$ & 1.519 & 1.537 \\
\hline Smallest $\mathrm{H}-\mathrm{Ni}-\mathrm{H}$ bond angle $\left({ }^{\circ}\right)$ & $103.4, \mathrm{H}(1)$ to $\mathrm{H}(4)$ & $107.8, \mathrm{H}(1)$ to $\mathrm{H}(2)$ \\
\hline Largest $\mathrm{H}-\mathrm{Ni}-\mathrm{H}$ bond angle $\left({ }^{\circ}\right)$ & $119.3, \mathrm{H}(1)$ to $\mathrm{H}(3)$ & $111.3, \mathrm{H}(1)$ to $\mathrm{H}(3)$ \\
\hline
\end{tabular}

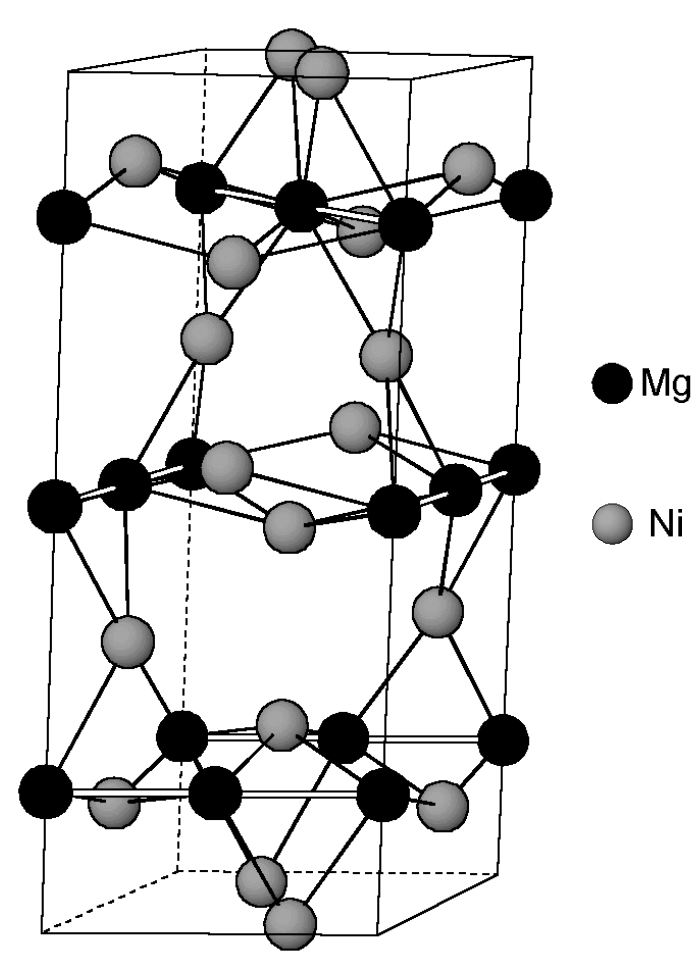

Figure 2. Crystal structure of $\mathrm{Mg}_{2} \mathrm{Ni}$ (after Ref. 26).
$\mathrm{Mg}_{2} \mathrm{Ni}$

We also calculated the atomic structure of $\mathrm{Mg}_{2} \mathrm{Ni}$ for use in calculating the enthalpy of formation of $\mathrm{Mg}_{2} \mathrm{NiH}_{4}$. Although Garcia et al. calculated a hypothetical cubic antifluorite form of $\mathrm{Mg}_{2} \mathrm{Ni}$, there appear to be no previous ab initio calculations for the hexagonal form. This is a layered structure with 12 $\mathrm{Mg}$ atoms and $6 \mathrm{Ni}$ atoms per cell as shown in

Figure 2. There are six layers parallel to the $x y$ plane per unit cell. Every other layer contains nickel atoms, occupying the fixed $3 \mathrm{~b}$ and $3 \mathrm{~d}$ lattice sites of space group $\mathrm{PG}_{2} 22$ and forming chains of strongly-bonded $\mathrm{Ni}$ atoms. The $\mathrm{Mg}$ atoms occupy lattice sites $6 \mathrm{i}$ and 6f, whose locations are determined by the free parameters $x$ and $z$, respectively. Starting with the experimentally determined atom positions ${ }^{26}$ and fixing the lattice constants, we minimized the total energy with respect to the $\mathrm{Mg}$ atom positions. Table 4 shows that the PW minimum energy configuration is nearly identical to the structure obtained by neutron diffraction and that relaxing the atomic positions had little effect on the total energy. 
Table 4. Experimental And Minimum Energy Configurations of $\mathrm{Mg}_{2} \mathrm{Ni}$ Energy in eV per formula unit. The experimental lattice constants ${ }^{25} \mathrm{a}=$ $5.205 \AA, c=13.236 \AA$ were used in both cases. $x$ and $z$ are the unconstrained coordinates of the $\mathrm{Mg}$ atoms in $6 \mathrm{i}(\mathrm{x}, 2 \mathrm{x}, 0)$ and $6 f(1 / 2,0, \mathrm{z})$.

\begin{tabular}{|l|lll|}
\hline \multirow{2}{*}{ Experimental [21] } & \multicolumn{1}{|c}{$\mathrm{x}$} & \multicolumn{1}{c|}{$\mathrm{z}$} & Relative Energy \\
\cline { 2 - 4 } PW minimum energy & $0.1620(16)$ & $0.1187(8)$ & 0 \\
\hline
\end{tabular}

\section{Enthalpy Calculations}

\section{Enthalpy of LT to HT Phase Transformation}

A moderate amount of heat is required to convert the monoclinic LT phase of $\mathrm{Mg}_{2} \mathrm{NiH}_{4}$ to the cubic HT phase. The enthalpy of this phase change can be calculated by taking the difference of the computed energies of each phase. Comparing the unrelaxed (experimental) $\mathrm{LT} \mathrm{Mg}_{2} \mathrm{NiH}_{4}$ structure with the LDA minimum energy configuration of the HT phase yields $\Delta \mathrm{H}=0.325 \pm 0.03$ $\mathrm{eV}$ per formula unit. The uncertainty reflects the estimated convergence of the energy difference with respect to the plane-wave cutoff energy (compared to a 85 Ryd cutoff calculation) and the number of $\mathrm{k}$ points (compared to a $3 \times 3 \times 3 \mathrm{LT}$ k-point grid calculation). If we include the energy change in $\mathrm{LT} \mathrm{Mg}_{2} \mathrm{NiH}_{4}$ upon atomic relaxation we obtain $\Delta \mathrm{H}=0.385 \mathrm{eV}$ per formula unit.

Experimental values vary from $\Delta \mathrm{H}=0.068$ to $0.086 \mathrm{eV}$ per formula unit, ${ }^{27}$ much smaller than the calculated value. One possible explanation for this discrepancy is that the HT structure considered by Garcia et al. is not the lowest energy cubic $\mathrm{Mg}_{2} \mathrm{NiH}_{4}$ structure. In the LT structure of $\mathrm{Mg}_{2} \mathrm{NiH}_{4}$, the eight $\mathrm{NiH}_{4}$ complexes have four different orientations, ${ }^{13}$ while the symmetry assumed for the HT structure forces all $\mathrm{NiH}_{4}$ units to have the same orientation. Neutron scattering data ${ }^{28}$ indicate that the positions of the hydrogen atoms in the HT phase fluctuate around the central $\mathrm{Ni}$ atom with a time scale of $10^{-11} \mathrm{~s}$. It therefore seems possible that a lower energy HT phase could be formed by expanding the unit cell and allowing the $\mathrm{NiH}_{4}$ units to assume different spatial orientations.

\section{Enthalpy of Hydrogen Absorption}

The heat of formation of $\mathrm{Mg}_{2} \mathrm{NiH}_{4}$ from $\mathrm{H}_{2}$ and $\mathrm{Mg}_{2} \mathrm{Ni}$ can also be calculated. We computed the energy of $\mathrm{H}_{2}$ gas by using a $6.3 \AA$ cubic supercell containing two $\mathrm{H}$ atoms separated by $0.741 \AA$. The computed enthalpy of hydrogen absorption to form $\alpha=21.8^{\circ} \mathrm{HT} \mathrm{Mg}_{2} \mathrm{NiH}_{4}$ is $\Delta \mathrm{H}=-2.06 \mathrm{eV}$ per formula unit. Relaxing the atomic positions using the PW method changes this value by only $0.01 \mathrm{eV}$ (Table 1). Experimental enthalpies range from $\Delta \mathrm{H}=-0.0980$ to $-1.36 \mathrm{eV}$ per formula unit. $^{27}$ 


\section{Electronic Structure and Optical Properties}

\section{Electronic structure of $\mathrm{Mg}_{2} \mathrm{NiH}_{4}$}

The calculated band structure of LT $\mathrm{Mg}_{2} \mathrm{NiH}_{4}$ is shown in Figure 3(a). K1 represents the Brillouin zone edge along the reciprocal lattice vector corresponding to the long axis $\left(a_{0}\right)$, while $\mathrm{K} 2$ is the Brillouin zone edge in the direction of the unique monoclinic axis. The band structure of cubic $\mathrm{Mg}_{2} \mathrm{NiH}_{4}$ with an undistorted tetrahedral hydrogen configuration, calculated using the PW method is shown in Figure 3(b). The latter is nearly identical to the LAPW structure in Ref. 8. Note that the band gaps in these two structures are almost the same, while that of the minimum energy HT $\mathrm{Mg}_{2} \mathrm{NiH}_{4}$ structure is zero. ${ }^{8}$ The density of states for $\mathrm{LT} \mathrm{Mg}_{2} \mathrm{NiH}_{4}$ and undistorted tetrahedron $\mathrm{HT} \mathrm{Mg}_{2} \mathrm{NiH}_{4}$ are plotted in Figure 4. In both cases, there are four lowlying bands per formula unit. These are $\mathrm{H}$ states, and they are separated by a gap from another five occupied bands. These five bands are the Ni $3 \mathrm{~d}$ bands. The $\mathrm{Mg} 3 \mathrm{~s}$ bands are unoccupied, indicating that each $\mathrm{Mg}$ donates two electrons to the $\mathrm{NiH}_{4}$ complex. Both $\mathrm{LT} \mathrm{Mg}_{2} \mathrm{NiH}_{4}$ and undistorted tetrahedron cubic $\mathrm{Mg}_{2} \mathrm{NiH}_{4}$ are indirect semiconductors. In $\mathrm{LT} \mathrm{Mg}_{2} \mathrm{NiH}_{4}$, the indirect gap occurs halfway between $\Gamma$ and $\mathrm{K} 2$ in the conduction band, while in undistorted tetrahedron cubic $\mathrm{Mg}_{2} \mathrm{NiH}_{4}$, the indirect transition is from valence band $\Gamma$ point to conduction band $\mathrm{X}$ point. The lower conduction bands are $\mathrm{Ni} 4 \mathrm{~s}$ orbitals plus some components of $\mathrm{Mg} 3 \mathrm{~s}$ orbitals for both systems. The similarity of these two systems demonstrates that the electronic structure is mainly controlled by the isolated $\mathrm{NiH}_{4}$ complex. The interaction between $\mathrm{NiH}_{4}$ pairs and the presence of $\mathrm{Mg}^{2+}$ ions play only minor roles.

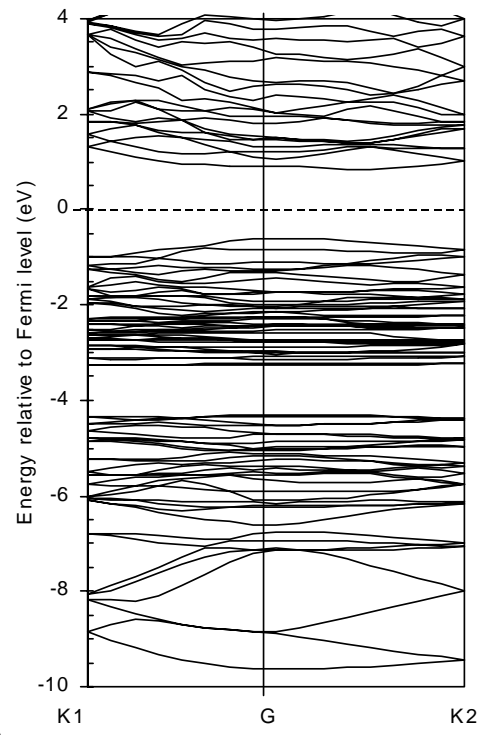

(a)

Figure 3. Electronic band structures for $\mathrm{Mg}_{2} \mathrm{NiH}_{4}$ : (a) $\mathrm{LT}$ monoclinic phase; (b) HT cubic phase with distorted tetrahedral $\mathrm{NiH}_{4}$. 


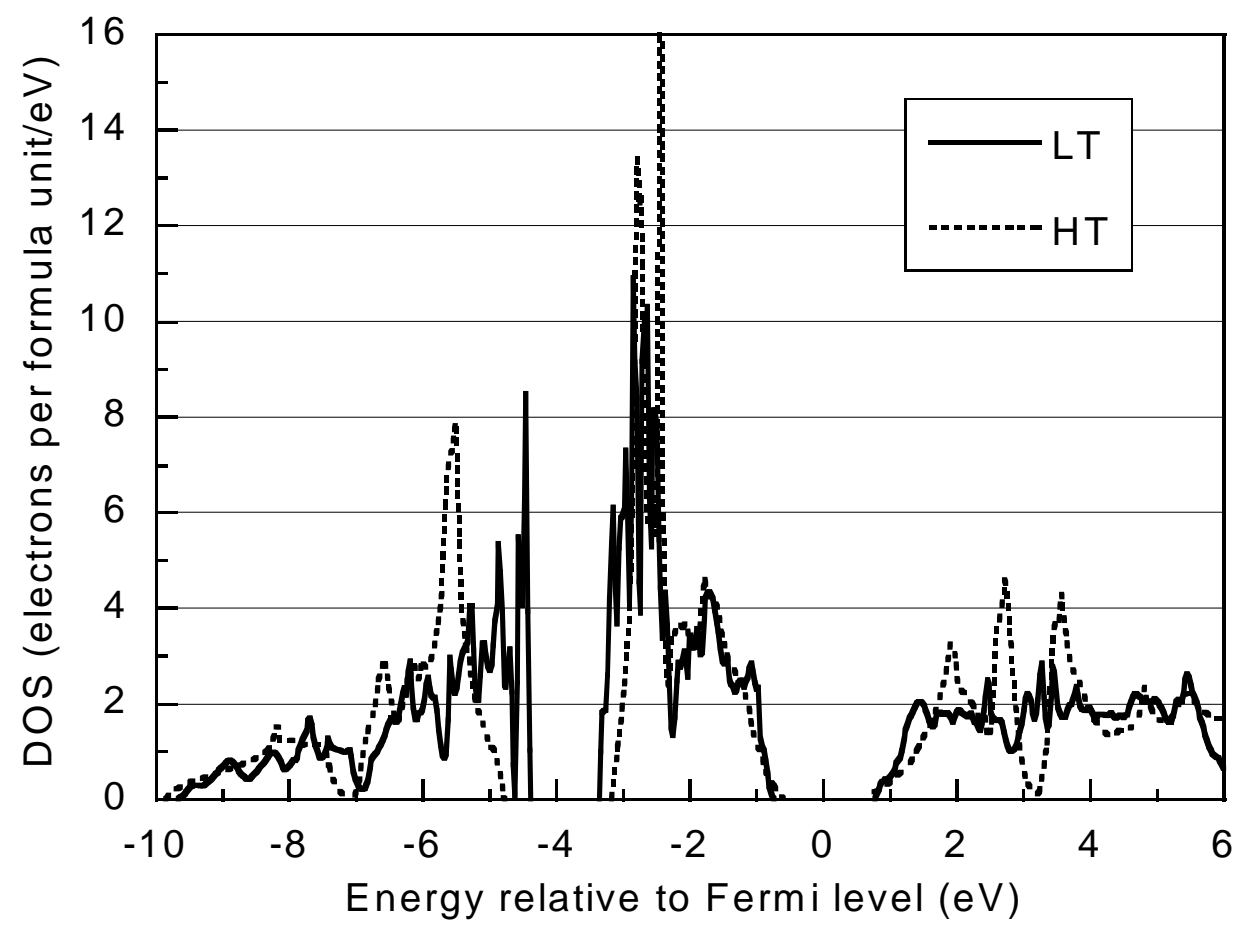

Figure 4. Electronic density of states for LT Mg2NiH4 (solid line) and HT $\mathrm{Mg} 2 \mathrm{NiH} 4$ with regular tetrahedral $\mathrm{NiH} 4$ (dashed line)

Optical Properties of $\mathrm{Mg}_{2} \mathrm{NiH}_{4}$

Imaginary Dielectric Constant

In Figure 5 the imaginary part of the dielectric constant $\left(\varepsilon_{2}\right)$ is plotted as a function of photon energy for both HT and LT configurations. For the HT phase, we show the results for the three $\mathrm{NiH}_{4}$ configurations: square planar, distorted tetrahedron (lowest energy), and undistorted tetrahedron. Because the calculations do not include Drude absorption, they underestimate the low-energy value of $\varepsilon_{2}$ for the metallic square planar hydrogen configuration. The other three structures have optical band gaps ranging from 1.9 to $2.4 \mathrm{eV}$; experimental measurements range from 1.3 to $2.0 \mathrm{eV}^{20,29-31}$ As the band gaps are indirect, the optical band gap is larger than the indirect band gaps shown in Figures 3 and 4. In contrast to the HT cubic phases where $\varepsilon_{2}$ rises from zero abruptly, $\varepsilon_{2}$ for the LT structure has a shoulder extending to its indirect band gap. This is due to the lower symmetry of the LT structure, which makes the forbidden transition in the HT case allowed. This shoulder accounts for the $0.5 \mathrm{eV}$ lower optical band gap of $\mathrm{LT} \mathrm{Mg}_{2} \mathrm{NiH}_{4}$ as compared with HT $\mathrm{Mg}_{2} \mathrm{NiH}_{4}$ with undistorted tetrahedral $\mathrm{NiH}_{4}$ geometry. 


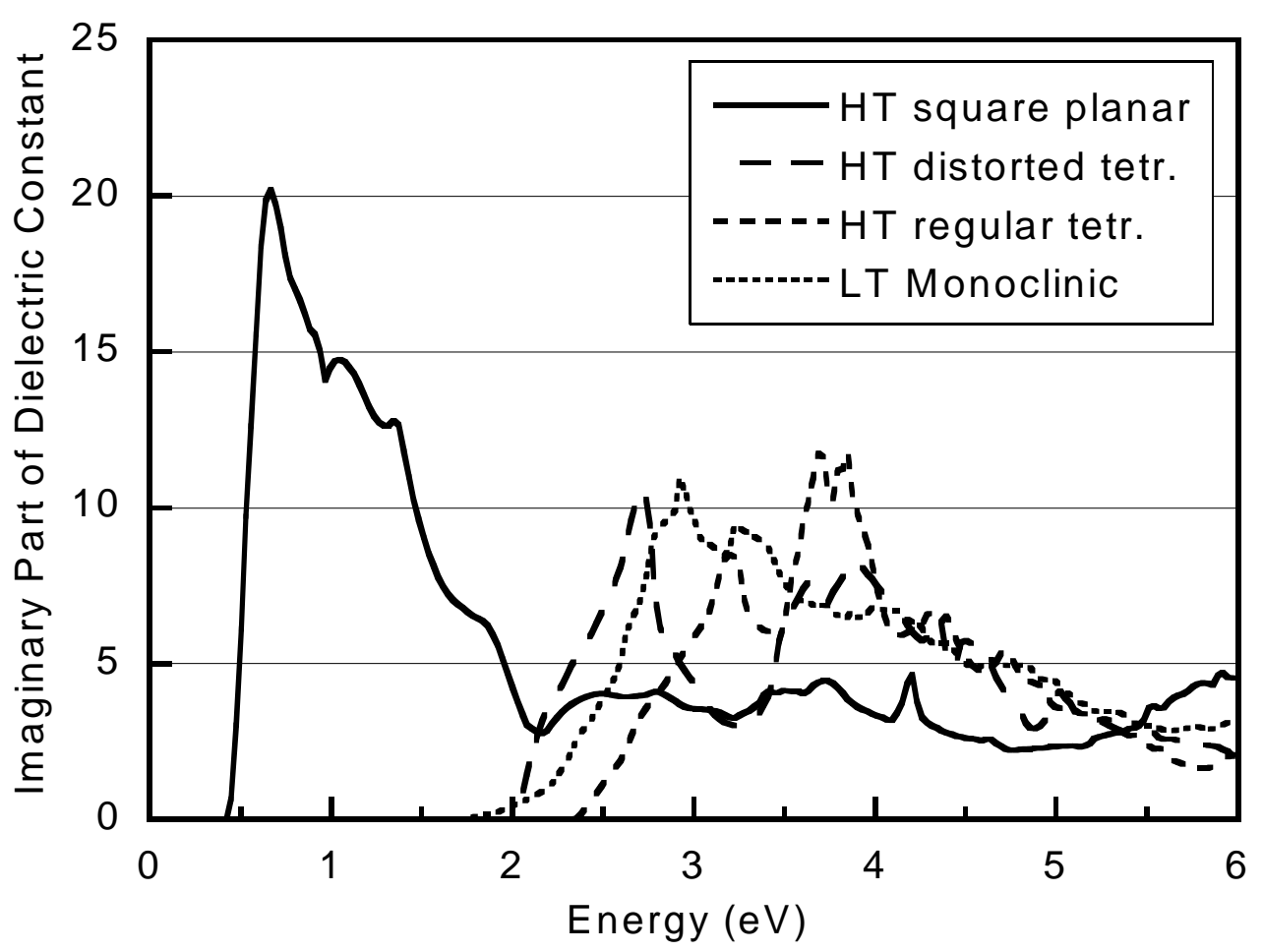

Figure 5. The imaginary part of the dielectric constant $\left(\varepsilon_{2}\right)$ vs. photon energy for HT and LT configurations.

\section{Thin Film Transmittance}

We compared the computed optical properties with measurements of the transmittance of a thin film of $\mathrm{Mg}_{2} \mathrm{NiH}_{4}$. A $1.0 \mu \mathrm{m}$ thick $\mathrm{Mg}_{2} \mathrm{Ni}$ film was prepared on a fused silica substrate by cosputtering of $\mathrm{Ni}$ and $\mathrm{Mg}^{3}$ A $10 \mathrm{~nm}$ Pd overlayer was added to catalyze hydrogen absorption. Exposure to gaseous hydrogen converted the film to $\mathrm{Mg}_{2} \mathrm{NiH}_{4}$ and caused it to expand to $1.3 \mu \mathrm{m}$ in thickness. The measured transmission of the thin film and a calculated spectrum using the dielectric functions in Figure 5 are shown in Figure 6. The sample is too thick to reveal features above the optical band gap, thus we will concentrate on the lower energy region. The overall agreement between the measured and modeled transmissions might not look good at first glance. This is probably due to the complexity of our sample and the simplicity of our model. The thin film transmission below the band gap is much lower than the modeled absorption because opaque imperfections in the film partially block the transmission beam. The amplitude of the oscillations in the measured transmission is much smaller than that in the modeled one, which may be due to surface roughness, which reduces the experimental amplitude of the interference fringes. Nevertheless, there are some important features that can be compared between the measured and modeled spectra. The optical band gap of the thin film lies between the band gaps of the two cubic structures and fits the LT structure best. Between 1.3 and $1.65 \mathrm{eV}$, both the experimental data and the LT structure model go through 3 fringes. Because the optical path length of the sample determines the frequency of these fringes, we believe that the real part of the calculated dielectric constant to be approximately correct in this region. 


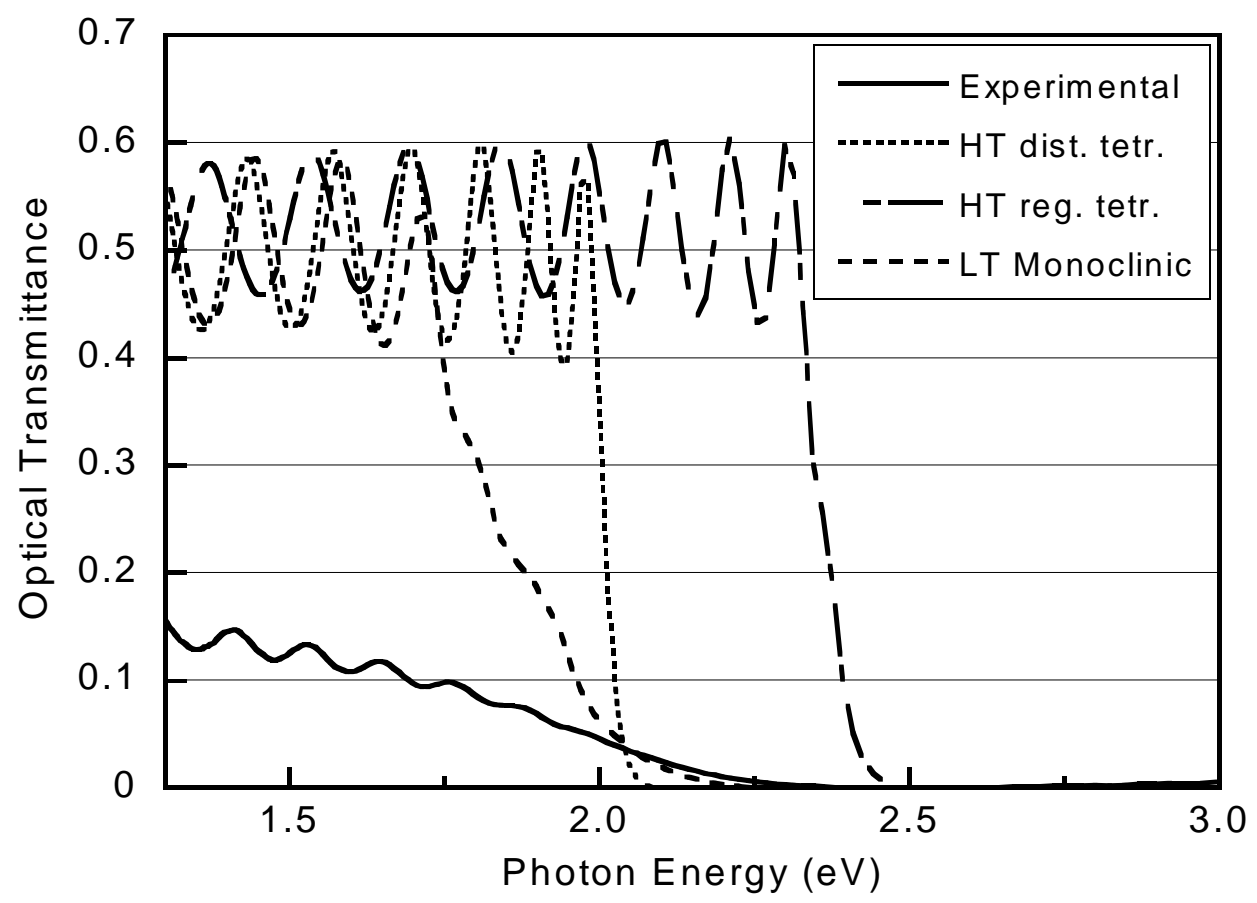

Figure 6. Experimental and calculated optical transmission spectra of $1.3 \mu \mathrm{m}$ thick $\mathrm{Mg}_{2} \mathrm{NiH}_{4}$ film.

\section{Conclusions}

The recent discovery of electrochromism in $\mathrm{LT} \mathrm{Mg}_{2} \mathrm{NiH}_{4}$ highlighted the need for ab initio calculations on this compound, especially for its optical properties. Such a study is possible due to recent advances in computational algorithms and large-scale parallel computers. Comparing the PW results with the LAPW results, we found that the two methods placed three atomic configurations of $\mathrm{HT} \mathrm{Mg}_{2} \mathrm{NiH}_{4}$ in the same order according to total energy. The PW method is shown to be a reliable and efficient method to study complex systems like $\mathrm{LT} \mathrm{Mg}_{2} \mathrm{NiH}_{4}$.

Our calculated minimum energy atomic positions are close to the experimental values for LT $\mathrm{Mg}_{2} \mathrm{NiH}_{4}$. The maximum position difference is about $0.14 \AA$. The $\mathrm{NiH}_{4}$ complex is a near perfect tetrahedron. This is in contrast with the cubic $\mathrm{HT} \mathrm{Mg}_{2} \mathrm{NiH}_{4}$ structure, where a flattened tetrahedron is found. This difference may be due to the different Madelung energies from the surrounding $\mathrm{Mg}^{2+}$ ions in the HT and LT phases (Fig. 1). In turn, the shape of the $\mathrm{NiH}_{4}$ moiety determines the electronic structure and optical properties of the system. The calculated minimum energy structure of $\mathrm{Mg}_{2} \mathrm{Ni}$ also matches the experimental structure quite well.

The calculated LT $\mathrm{Mg}_{2} \mathrm{NiH}_{4}$ to $\mathrm{HT} \mathrm{Mg}_{2} \mathrm{NiH}_{4}$ transition enthalpy is considerably larger than reported experimental values. The calculated enthalpy of hydrogen absorption by $\mathrm{Mg}_{2} \mathrm{Ni}$ is also somewhat larger than expected. Possibly the hypothetical cubic structure is not the lowest energy HT structure. More extensive calculations involving a superlattice might yield a lower energy HT structure. 
The electronic structure of $\mathrm{LT} \mathrm{Mg}_{2} \mathrm{NiH}_{4}$ resembles that of cubic $\mathrm{Mg}_{2} \mathrm{NiH}_{4}$ with an undistorted tetrahedral hydrogen configuration. It is a semiconductor with an indirect band gap of $1.4 \mathrm{eV}$. The lower symmetry of $\mathrm{LT} \mathrm{Mg}_{2} \mathrm{NiH}_{4}$ produces a shoulder in its dielectric constant that does not appear in the HT phase. This reduces the optical gap by about $0.5 \mathrm{eV}$ compared to that of the HT $\mathrm{Mg}_{2} \mathrm{NiH}_{4}$ with an undistorted tetrahedral $\mathrm{NiH}_{4}$. The transmission spectrum of a thin film of $\mathrm{Mg}_{2} \mathrm{NiH}_{4}$ at room temperature is consistent with the calculated LT spectrum.

\section{Acknowledgements}

The authors thank Jonathan Slack of LBNL for experimental assistance. This work was supported by the Assistant Secretary for Energy Efficiency and Renewable Energy, Office of Building Technology, State and Community Programs, Office of Building Research and Standards of the US Department of Energy under Contract No. DE-AC03-76SF00098. This research used resources of the National Energy Research Scientific Computing Center, which is supported by the Office of Science of the U.S. Department of Energy. Work at NERSC was supported by the Director, Office of Science, Division of Mathematical, Information, and Computational Science of the U.S. Department of Energy under Contract number DE-AC0376 SF00098.

\section{References}

1. J.J. Reilly, R.H. Wiswall, Inorg. Chem. 7 (1968) 2254.

2. T.J. Richardson, $4^{\text {th }}$ International Meeting on Electrochromism, Uppsala, Sweden, August 2000.

3. T.J. Richardson, J.L. Slack, R.D. Armitage, R. Kostecki, B. Farangis, M.D. Rubin, App. Phys. Lett. 78 (2001) 3047.

4. Z. Gavra, M.H. Mintz, G. Kimmel, Z. Hadari, Inorg. Chem. 18 (1979) 3595.

5. M. Gupta, E. Belin, L. Schlapbach, J. Less-Common Met. 103 (1984) 389.

6. P. Lindberg, D. Noreus, M. Blomberg, P. Siegbahn, J. Chem. Phys. 85 (1986) 4530.

7. N. Huang, Q. Wang, J. Wu, J. Tang, Z. Physikalische Chem. NF 163 (1989) S207

8. G.N. Garcia, J.P. Abriata, J.O. Sofo, Phys. Rev. B 59 (1999) 11746.

9. J. Schefer, F. Fischer, W. Hälg, F. Stucki, L. Schlapbach, J.J. Didisheim, K. Yvon, A.F. Andresen, J. Less-Common Met. 74 (1980) 65.

10. K. Yvon, J. Schefer, F. Stucki, Inorg. Chem. 20 (1981) 2776.

11. P. Zolliker, K. Yvon, Mat. Res. Bull. 21 (1986) 415.

12. P. Blaha, K. Schwarz, J. Luitz, WIEN97, CVienna University of Technology, Vienna 1997. Improved and updated Unix version of WIEN: P. Blaha, K. Schwarz, P. Sorantin, S. B. Trickey, Comput. Phys. Commun. 59 (1990) 399.

13. P. Zolliker, K. Yvon, J.D. Jorgensen, F.J. Rotella, Inorg. Chem. 25 (1986) 3590. 
14. P. Hohenberg, W. Kohn, Phys. Rev. 136 (1964) 864.

15. W. Kohn, L.J. Sham, Phys. Rev. 140 (1965) 1133.

16. N. Trouillier, J.L. Martins, Phys. Rev. B 43 (1991) 1993.

17. L. Kleinman, D.M. Bylander, Phys. Rev. Lett. 48 (1982) 1425.

18. M.P. Teter, M.C. Payne, D.C. Allan, Phys. Rev. B 40 (1989) 12255.

19. W.H. Press, S.A. Teukolsky, W.T. Vetterling, and B.P. Flannery, Numerical Recipes in Fortran, Cambridge University Press, New York, 1992.

20. P. Selvam, B. Viswanthan, and V. Srinivasan, J. Electron Spectrosc. Relat. Phenom. 46 (1988) 357.

21. S. Froyen, Phys. Rev. B 39 (1989) 3168.

22. P.E. Blochl, O. Jepsen, O.K. Andersen, Phys. Rev. B 49 (1994) 16223.

23. P.Y. Yu, M. Cardona, Fundamentals of Semiconductors : Physics and Materials Properties, Springer:Berlin, 1996, New York, pp. 242-255.

24. For information on Petot, see: http://www.nersc.gov/ linwang/PEtot/PEtot.html.

25. A. Canning, L.W. Wang, A. Williamson, A. Zunger, J. Comp. Phys. 160 (2000) 29.

26. J.L. Soubeyroux, D. Fruchart, A. Mikou, M. Pezat, B. Darriet, Mater. Res. Bull. 19 (1984) 895.

27. K. Zeng, T. Klassen, W. Oelerich, R. Bormann, J. Alloys Comp. 283 (1999) 213.

28. D. Noreus, L.G. Olsson, J. Chem. Phys. 78 (1983) 2419.

29. D. Lupu, R. Sarbu, A. Biris, Int. J. Hydrogen Energy 12 (1987) 425.

30. D. Lupu, R. Grecu, S.I. Farcas, Z. Physik. Chem. 181 (1993) 143.

31. Y. Fujita, M. Yamaguchi, I. Yamamoto, Z. Physik. Chem. 163 (1989) 633.

32. J. Sofo, personal communication. 